\title{
DRAWING THE OPTIMAL DEPTH-AGE CURVE ON THE BASIS OF CALIBRATED RADIOCARBON DATES
}

\author{
ADAM WALANUS \\ Department of Geoinformatics and Applied Computer Science \\ AGH University of Science and Technology \\ Al. Mickiewicza 30, 30-059 Kraków, Poland
}

Received 27 June 2007

Accepted 9 January 2008

\begin{abstract}
The radiocarbon determination of age has the form of a complicated probability density function. In some cases however it is possible to exploit it in a precise way, in drawing the depth-age curve when a stratigraphic sequence of ${ }^{14} \mathrm{C}$ ages is available. It is also possible to use this function in drawing the depth-age curve by hand. The necessary additional constraint on the depth-age curve adopted here is the simplicity of its shape, namely the low curvature.
\end{abstract}

Keywords: radiocarbon dating, calibration, probability distribution, likelihood, depth-age.

\section{INTRODUCTION}

The final result of the radiocarbon dating of a sample taken from some depth in a profile has a complicated form of probability distribution of shape resembling an Alpine-type landscape (Fig. 1) rather than the typical bell-shaped curve. There is no single value of estimated age but a probability distribution over some range of ages (see, for example, discussion in Telford et al., 2004). However, this situation is not completely different from that of the so-called conventional radiocarbon dates which are normally (Gauss) distributed. The only difference is that calibrated age distribution is multimodal, i.e. it has many "peaks". However, this is not necessarily a drawback. The simple, symmetric, bell-shape curve of conventional ${ }^{14} \mathrm{C}$ date distribution may rather be treated as misleading because it suggests that one strict value of age can be picked up as a date, while it is still a distribution over, say, $\pm 3 \sigma$ around the mid-value.

Regardless of how complicated the shape of the probability distribution is, it is possible to include it into precise, probabilistic calculations necessary in the construction of the depth-age curve. However, this requires rather intensive computer calculations, but the method presented below (its idea), can also be applied to drawing the depthage "by hand". The lack of precision in such a case is

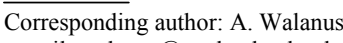

e-mail: walanus@geol.agh.edu.pl

ISSN 1897-1695 (online), 1733-8387 (print) (C) 2008 GADAM Centre, Institute of Physics, Silesian University of Technology.

All rights reserved. much smaller than that expected from the comparison of the human and machine computing power. Generally, the subjective natural scientist opinion is frequently underestimated in comparison to the "sophisticated" mathematical models (Bennett and Fuller 2002, Heegaard et al., 2005).

The method presented here is based on two general constraints of the depth-age curve. The first constraint is imposed by the set of radiocarbon dates available for the profile. However, this is not sufficient, because many different curves can be drawn "through" the dates, even if the dates were treated as precise values of age, not probability distributions. The second, necessary constraint is connected to the shape of the depth-age curve and it must define the shape of the curve in the sections between dates. In general, it is reasonable to assume that the depth-age curve should be as smooth (simple) as possible.

\section{THE CONCORDANCE OF THE DEPTH-AGE CURVE WITH DATES}

The depth-age curve considered here is assumed to be unequivocal. This means that it is simply the curve, not the band of, for example, a confidence interval. If so, the curve precisely defines the age at each depth, especially at depths where radiocarbon samples have been taken. Of course, such an age has to be concordant with the probability distribution of the radiocarbon determination 
(Fig. 1). For the given age $T$, and for the given radiocarbon date, there is a strictly defined value of the probability density $f(T)$. For all $N$ dates made in the profile, there are $N$ values of the function $f_{i}\left(T_{i}\right)$, where $T_{i}$ is the age, according to the depth-age curve, at the depth of the i-th date.

The depth-age curve must meet all of the radiocarbon dates in the profile. This means that none of the $f_{i}\left(T_{i}\right)$ 's could be zero or close to zero. The mathematical formula which quantifies such a constraint, is that of likelihood (the notion, used by the author in such a context in public presentation for the first time in October 2004, Walanus, Wasylikowa 2004), i.e. the multiplication of all $f_{i}\left(T_{i}\right)$; $L=f_{l}\left(T_{l}\right) \cdot f_{2}\left(T_{2}\right) \cdot \ldots \cdot f_{N}\left(T_{N}\right)=\Pi f_{i}\left(T_{i}\right)$. The value of $L$ is simply to be as large as possible, for the depth-age curve to be accepted as concordant with the radiocarbon dates.

It is easy to find exactly the largest value of $L$. The ages $T_{i}^{\text {top }}$ are to be found that maximise $f_{i}\left(T_{i}^{\text {top }}\right)$, which means that $T_{i}^{\text {top }}$ indicates the position of the highest point (Fig. 1). However, the depth-age curve drawn through all $T_{i}^{\text {top }}$ would be optimal only from the point of view of ${ }^{14} \mathrm{C}$ dating, but it would probably be much less optimal from the point of view of the simplicity of the depth-age model.

Keeping in mind that $f_{i}\left(T_{i}\right)$ is "only" a probability, any other $T_{i}$ age can be accepted instead of exactly $T_{i}^{\text {top }}$, even if it gives the $f_{i}\left(T_{i}\right)$ value, say, only half of the maximum $f_{i}\left(T_{i}^{\text {top }}\right)$. Accepting that, for each date, quite a large span of values for $T_{i}$ is allowed, it gives some freedom to choose a nice shape of the depth-age curve. The value of $L$ needs not be precisely maximal. However, in practice it is frequently very close to the maximal value. It depends on how self-consistent the set of radiocarbon dates is, especially if there are no outliers (Buck et al., 2003) in the data.

In order to calculate the value of $L$, a computer is necessary. What is more difficult, however, are the necessary functions $f_{i}\left(T_{i}\right)$; in numerical form, not only as a plot. Typical calibration programs (Bronk Ramsey, 2001) rarely give the resulting function in the text form (like: ... $2345 \mathrm{BC}-0.85,2346 \mathrm{BC}-0.84, \ldots)$. It is possible to create a special calibration program, using for example MS Excel (calibration data are available (Reimer et al., 2004)), however, the other possible way is to prepare a program for reading out the relative heights of the probability function plotted by any professional calibration program. The possible precision of such a graphical method is good enough. In fact, such a plot can be used immediately, with no further processing, for a generation of random ages (see below).

Keeping in mind that the value of $f(T)$ has the sense of probability, the hand-drawn method may be recommended as a method for creating the depth-age curve instead of precise calculations. Instead of calculating $L$, it may be enough to use such ages $T_{i}$, which do not have overly low values of $f_{i}\left(T_{i}\right)$. The simplest way is to use the $95 \%$ confidence interval given by the calibration program, and to treat ages from that interval as allowed, and those from the outside as prohibited. However, seeing the shape of the $f(T)$ function (as in Fig. 4), it is easy to keep in mind some idea of how low the probability of the chosen $T$ is. If all or many of $N$ values of $f_{i}\left(T_{i}\right)$ are relatively

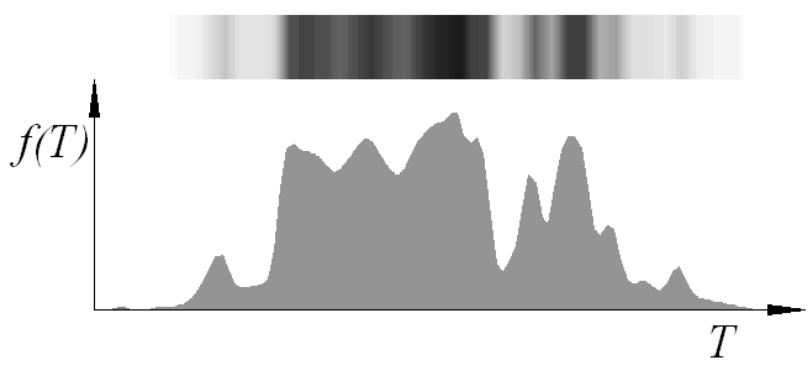

Fig. 1. The result of radiocarbon dating - the probability density function $f(T)$, as a function of age $T$. The upper section presents the view of the Alpine-type function as "seen" by the bird's eye. Such picture, in grey-scale, seems to resemble reality better, since $f(T)$ is the "only" probability, not a "hard" quantity such as age or depth (it is an opposite point of view to presented by Benett (1994) considering "precise confidence intervals"). The scale of the grey is chosen so that the zero probability is white, and the maximal probability is black. It is not good practice, but broadly accepted, to assign some absolute value ("black" or "1") to the maximal value of a particular density function. From another point of view, however, the true values of $f(T)$, which are of the order of 0.01 year $^{-1}$, are of little practical use.

low (the $L$ is low in such a case), this means that the depth-age curve is not in good agreement with the radiocarbon dates.

\section{THE SIMPLICITY OF THE DEPTH-AGE CURVE}

It is a general rule in the scientific method, to have as simple a model as possible (basing on all accessible information). In the case of the depth-age curve that rule can by expressed mathematically as the principle of minimisation of the curve's curvature. Of course, a typical depth-age curve is not a fragment of a circle, and does not have a single value of the curvature. But it is not difficult to define the average curvature of any continuous line. It must be mentioned, however, that the first derivative of the curve, i.e. the sedimentation rate, should also be continuous. This means that no instant changes in the sedimentation rate are assumed to occur. If this is not the actual case (there are distinct boundaries present in the sediment), the idea of the simplicity of the depth-age curve is to be slightly reformulated because the curvature approaches infinity at the boundaries.

In such a case, the depth-age curve can have the form of a broken line connecting the points $\left(T_{i}, d_{i}\right)$, defined by the depth $(d)$ and the age $(T)$. The idea of simplicity can be transformed to the rule stating that the slopes of the neighbouring sections of the broken line may not differ too much.

In the example below (Fig. 5c) a smooth depth-age curve is used, with no radical changes in sedimentation rate. The curve is composed of "cubic splines". These are pieces of such polynomials of the third order that, when connected with one another in the points $\left(T_{i}, d_{i}\right)$, create a smooth line with no bends (not V, only $\mathrm{U}$ or S-shaped connections).

The average curvature is calculated based on partial curvatures calculated for small (e.g. 30-cm-long) pieces of the profile (Fig. 2). The partial curvature is the difference between the age according to the curve, and the age 
according to the interpolation (see Fig. 2). The final, general measure of the curvature $C$ is defined as the sum of squares of all partial curvatures. The rationale for taking squares is not only to remove the possible negative sign of the measure of curvature, but also to increase the significance of pieces with an especially high curvature. It is important to avoid even small fragments with bends or wiggles.

A lower average curvature $C$ means a better depth-age curve (in the sense of simplicity).

If the method of manual plotting of the depth-age curve is adopted, it is also possible to simply avoid high curvatures or abrupt changes in slope.

\section{GENERATION OF THE BEST DEPTH-AGE CURVE}

For the given depth-age curve the value of $L$ and $C$ can be calculated. However, the problem is how to find the curve with the highest possible $L$, and the lowest possible $C$. The computer-intensive Monte Carlo method can be used here. Many (very many) sensible curves are created and examined for $L$ and $C$. Of course, it may be expected that a different curve will give the highest $L$, and different one will give the lowest $C$. In fact, some compromise is necessary.

The algorithm of obtaining the best depth-age curve is as follows. Using a fast computer (i.e. the typical, contemporary one), do: (1) for each i-th date generate the value of age $T_{i}$ (see description below for instructions), (2) draw cubic splines through the points $\left(T_{i}, d_{i}\right)$, i.e. produce the depth-age curve, (3) calculate $L$ and $C$, (4) repeat points (1)-(3) 1,000 or 10,000 times, (5) chose the curve with a high $L$ and low $C$ (Fig. 3), (6) inspect the chosen curve visually.

The generation of the value of the age $T_{i}$, in principle should be based on the respective i-th radiocarbon date

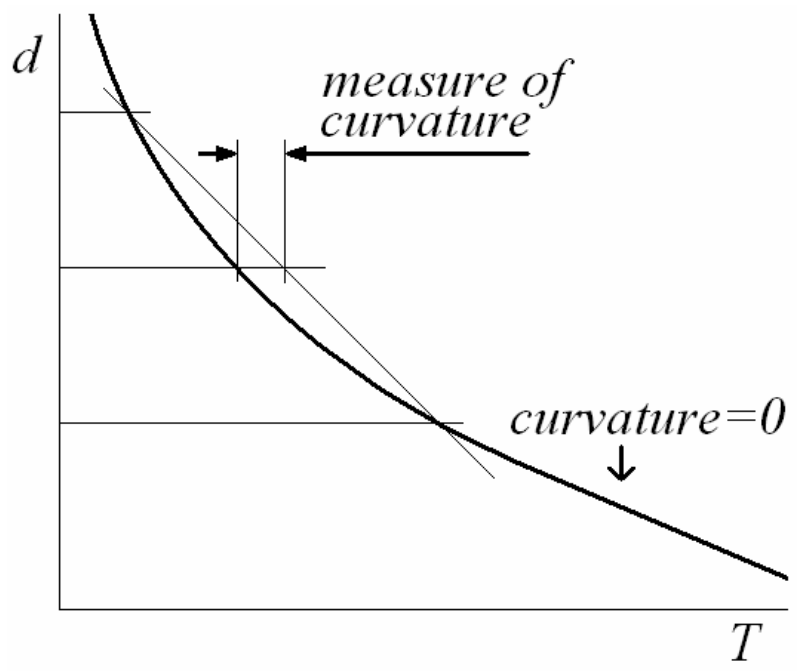

Fig. 2. The measure of the curvature of the depth (d)-age (T) curve. The full depth-span of the profile is divided into many small pieces (such as the one presented here), and the measure of curvature for all the pieces is calculated. The resulting, average curvature $(C)$ for the curve is defined as the sum of squares of all partial curvatures, divided by its number. (probability density function), however this is not actually necessary as the value of $L$ is calculated in the next step. The values of $T_{i}$ would be taken randomly, according to the uniform distribution from the age span which contains all the probability distribution. It is only a question of economy of calculations, i.e. how many depth-age curves are to be produced in order to find one that is good enough.

A faster way is to take $T$ from the true distribution, not the approximated uniform. The method of generation is easy, and it can be instructive also in the case of the manual creation of the depth-age curve. The steps are as follows: (1) let $T_{\min }$ and $T_{\max }$ denote the minimal and maximal age possible according to the radiocarbon result, (2) take a random (uniformly distributed) value $T$ from the interval $\left(T_{\min }, T_{\max }\right)$, (3) take the next random, uniform value $x$ from the interval $\left(0, f_{\max }\right)$, where $f_{\max }$ is the value of the highest peak of the age distribution (may be $\left.f_{\max }=1\right)$, (4) if $x<f(T)$ then accept $T$ as the age, otherwise go to (2).

\section{EXAMPLE}

The exemplary profile from Lake Zeribar, Zagros Mountains, Iran (Snyder et al., 2001, Wasylikowa and Walanus 2004, Wasylikowa et al., 2006) covers the timespan from the Pleniglacial to the youngest Holocene. In this record there are also dates which are too old to be calibrated by the precise radiocarbon calibration curve (Intcal 04 - Reimer et al. 2004), however, approximate calibration is possible (Hughen et al., 2004). The oldest radiocarbon dates in Fig. 4 have the form of normal (Gaussian) probability distribution which does not create any problems in applying the method described above.

Since the 3D (axonometric) plot is not suitable for any operations other than visual inspection, for plotting

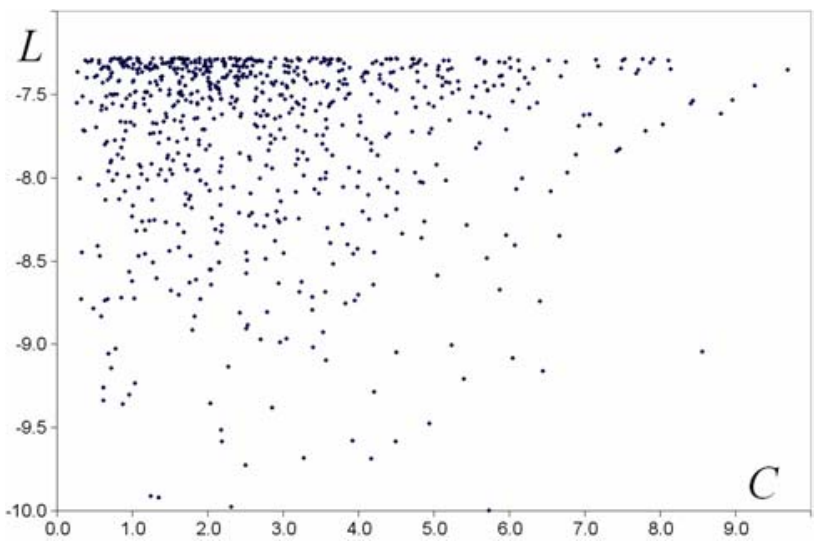

Fig. 3. The plot of points $(C, L)$, i.e. the values of likelihood $L$ of ages (according to the radiocarbon determinations), and the average curvature $C$ of the depth-age curve. (The logarithm of $L$ is in fact plotted here.) Each point corresponds to one depth-age curve. The best curves are those from the upper-left corner. Since there is no one "precisely" best point, two or three curves could be inspected visually, however, differences generally are negligible. It is probably more important to have a lower $C$ than the really topmost $L$, since $L$ is based on probability only, while $C$ precisely reflects the shape of the curve. You can see that many curves approach the best $L(-7.25)$, while few have Cs close to zero. 


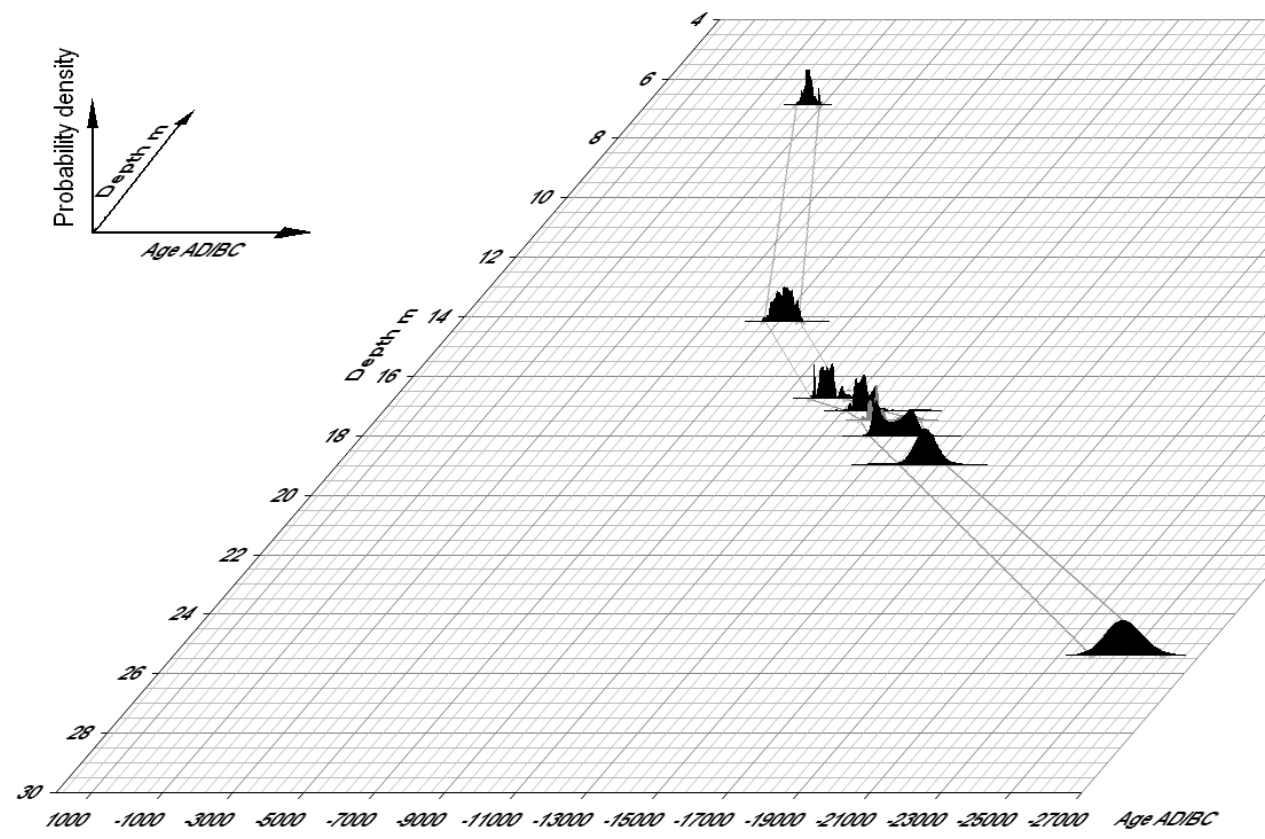

Fig. 4. The three-dimensional plot of the radiocarbon dates placed at respective depths, along the profile. The approximate $95 \%$-confidence band is also given, represented by broken lines plotted from date to date. The areas of the plotted probability density distributions are not normalised, which is incorrect, in principle. However, this is not a problem as long as the dates are not mixed. The height of the distributions is standardized, like in the typical calibration program. As a result, however, the more precise dates (narrow in sense of time) are the "smallest" ones here. The depth-age curve will define the point age for each depth. The depth-age curve is to go "through" the ${ }^{14} \mathrm{C}$ dates (how well this is done is measured by $L$ ). depth-age curve manually, the usual $2 \mathrm{D}$ plot is to be adopted. Consequently, in accordance with Fig. 4, the grey scale is used for radiocarbon dates in Fig. 5 because it is kind of a bird's-eye view. However, typical plots from calibrated programs may also be used.

A specialised computer program, or the scientist who possesses a priori knowledge about the profile, must draw the depth-age curve through the peaks, or at least through the higher parts of ${ }^{14} \mathrm{C}$ probability distributions, keeping the curve as smooth as possible. The difference between machine and personal drawing is mainly in that we know precisely what kind of knowledge a computer uses, while the influence of the subjective experience and the knowledge (stratigraphy, lithology, ...) is difficult to appreciate. It is disputable which method is better. The abstract, machine precision cannot guarantee correctness of the final result if one or more ${ }^{14} \mathrm{C}$ dates are incorrect. According to the common opinion: "... even in the most carefully managed radiocarbon dating projects ... each sample has a 1 in 10 chance of being an outlier" (Buck et al., 2003).

\section{ACKNOWLEDGEMENT}

This method has been developed in connection with the author's co-operation with Krystyna Wasylikowa. This work was sponsored by Statutory Funds of Department of Geoinformatics and Applied Computer Science, AGH University of Science and Technology, Kraków.

\section{REFERENCES}

Bennett KD, 1994. Confidence intervals for age estimates and deposition times in late-Quaternary sediment sequences. Holocene 4(4): 337-348, DOI 10.1177/095968369400400401.

Bennett KD and Fuller JL, 2002. Determining the age of the midHolocene Tsuga canadensis (hemlock) decline, eastern North America. Holocene 12(4): 421-429, DOI 10.1191/0959683602hl556rp.

Bronk Ramsey C, 2001. Development of the Radiocarbon Program OxCal. Radiocarbon 43(2A): 355-63.

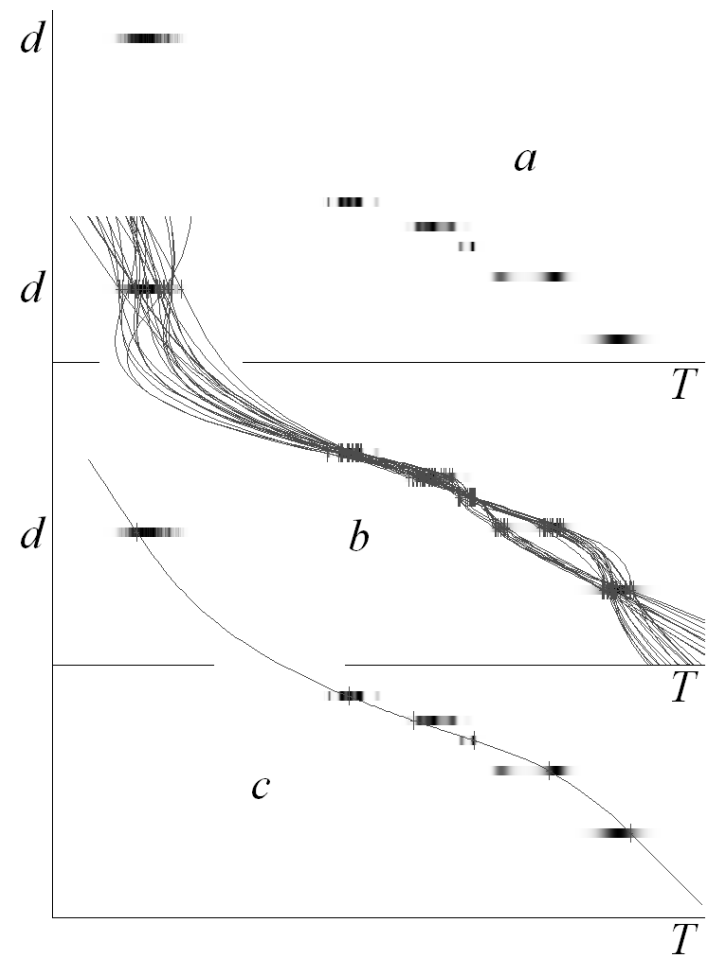

Fig. 5. The depth-age coordinates in the typical two-dimensional plot, with the radiocarbon dates plotted in grey scale (a), (see Fig. 1). The width of dates, in vertical scale, does not represent the real sample width. The oldest date from Fig. 4 is omitted here for clarity. A small fraction of the total number of all depth-age curves generated is presented at (b). The best curve (c) is that with the highest likelihood (L) according to ${ }^{14} \mathrm{C}$ determinations, and with the lowest possible curvature (as smooth as possible).

Buck CE, Higham TFG and Lowe DJ, 2003. Bayesian tools for tephrochronology. Holocene 13: 639-47.

Heegaard E, Birks HJB and Telford RJ, 2005. Relationships between calibrated ages and depth in stratigraphical sequences: an estimation procedure by mixed-effect regression. Holocene 15(4): 612 618. 
Hughen K, Lehman S, Southon J, Overpack J, Marchal O, Herring C and Turnbull J, 2004. ${ }^{14} \mathrm{C}$ activity and global carbon cycle changes over the past 50,000 years. Science 303: 202-7.

Reimer PJ, Baillie MGL, Bard E, Bayliss A, Beck JW, Bertrand C, Blackwell PG, Buck CE, Burr G, Cutler KB, Damon PE, Edwards RL, Fairbanks RG, Friedrich M, Guilderson TP, Hughen KA, Kromer B, McCormac FG, Manning S, Bronk Ramsey C, Reimer RW, Remmele S, Southon JR, Stuiver M, Talamo S, Taylor FW, van der Plicht J and Weyhenmeyer CE, 2004. IntCal04 terrestrial radiocarbon age calibration, $0-26$ cal kyr BP. Radiocarbon 46(3): 1029-58

Snyder JA, Wasylik K, Fritz SC and Wright Jr. HE, 2001. Diatom-based conductivity reconstruction and palaeoclimatic interpretation of a 40-ka record from Lake Zeribar, Iran. The Holocene 11: 737-45.
Telford RJ, Heegaard E and Birks HJB, 2004. The intercept is a poor estimate of a calibrated radiocarbon age. Holocene 14: 296-8.

Walanus A, Wasylikowa K, Wyznaczenie relacji głębokości do wieku w profilach Zeribar (Iran), na podstawie dat radioweglowych i korelacji palinologicznych. Conference: Problemy metodyczne interpretacji dat radiowęglowych, Rzeszów, 16 Oct. 2004.

Wasylikowa $\mathrm{K}$ and Walanus A, 2004. Timing of aquatic and marshplant successions in different parts of Lake Zeribar, Iran, during the Late Glacial and Holocene. Acta Palaeobotanica 44(2): 129140 .

Wasylikowa K, Witkowski A, Walanus A, Hutorowicz A, Alexandrowicz SW and Langer JJ, 2006. Palaeolimnology of Lake Zeribar, Iran, and its climatic implications. Quaternary Research 66: $477-$ 496. 